\title{
ON THE IN VITRO FATIGUE BEHAVIOR OF HUMAN DENTIN WITH IMPLICATIONS FOR LIFE PREDICTION
}

\author{
R. K. Nalla ${ }^{1}$, V. Imbeni ${ }^{1}$, J. H. Kinney ${ }^{2}$, M. Staninec ${ }^{2}$, S. J. Marshall ${ }^{2}$, and R. O. Ritchie M $^{1,3}$ \\ ${ }^{1}$ Materials Sciences Division, Lawrence Berkeley National Laboratory, and \\ Department of Materials Science and Engineering \\ University of California, Berkeley CA 94720 \\ ${ }^{2}$ Department of Preventive and Restorative Dental Sciences \\ University of California, San Francisco CA 94143 \\ ${ }^{3}$ Corresponding author: Tel: (510) 486-5798; fax: (510) 486-4881 \\ E-mail address: RORitchie@lbl.gov (R.O. Ritchie)
}

April 2002

submitted to

Journal of Biomedical Materials Research

This work was supported by the National Institutes of Health, National Institute of Dental and Craniofacial Research under Grant No. P01DE09859. 


\title{
ON THE IN VITRO FATIGUE BEHAVIOR OF HUMAN DENTIN WITH IMPLICATIONS FOR LIFE PREDICTION
}

\author{
R. K. Nalla ${ }^{1}$, V. Imbeni ${ }^{1}$, J. H. Kinney ${ }^{2}$, M. Staninec ${ }^{2}$, S. J. Marshall ${ }^{2}$, and R. O. Ritchie ${ }^{1, *}$ \\ ${ }^{1}$ Materials Sciences Division, Lawrence Berkeley National Laboratory, and \\ Department of Materials Science and Engineering \\ University of California, Berkeley CA 94720 \\ ${ }^{2}$ Department of Preventive and Restorative Dental Sciences \\ University of California, San Francisco CA 94143
}

\begin{abstract}
Although human dentin is known to be susceptible to failure under repetitive cyclic fatigue loading, there are few reports in the literature that reliably quantify this phenomenon. Accordingly, this study seeks to address the paucity of fatigue data through a systematic investigation of the effects of prolonged cyclical loading on human dentin in an environment of ambient temperature Hank's Balanced Salt Solution (HBSS) at cyclic frequencies of 2 and $20 \mathrm{~Hz}$. The "stress-life" $(S / N)$ data thus obtained are discussed in the context of possible mechanisms of fatigue damage and failure in this material. In addition, stiffness loss data collected in situ during the $S / N$ tests are used to deduce crack velocities and the thresholds for such cracking; such results are presented in a fracture mechanics context as plots of fatiguecrack propagation rates $(d a / d N)$ as a function of the stress-intensity range $(\Delta K)$. Such $S / N$ and $d a / d N-\Delta K$ data are discussed in light of the development of a framework for fracturemechanics based methodology for the prediction of the fatigue life in teeth. It is concluded that the presence of small incipient flaws in human teeth of the order of $250 \mu \mathrm{m}$ in size will not radically affect their useful life.
\end{abstract}

Keywords: Dentin, fatigue, $S / N$ behavior, fractography, sustained-load cracking, fatiguecrack growth, fatigue threshold, life prediction

\footnotetext{
* Corresponding author: Tel: (510) 486-5798; fax: (510) 486-4881

E-mail address: RORitchie@lbl.gov (R.O. Ritchie)
} 


\section{Introduction}

In human teeth, dentin lies between the exterior enamel and the pulpal soft tissue in the core (Fig. 1); it thus forms the bulk of the interior structure of the human tooth and is critical to its structural integrity. In light of this, it is important that the mechanical properties of dentin are fully characterized such that realistic predictions can be made for the effect of microstructural modifications due to caries, sclerosis and aging on tooth strength, not to mention the effect of various restorative processes commonly employed in dentistry. While several studies have focused on evaluating these properties [e.g., 1-15], there is very little consistency in the available data.

From a structural viewpoint, exposed root surfaces in teeth often exhibit non-carious notches in the dentin just below the enamel-cementum junction. The etiology for such lesions is believed to involve a combination of erosion, abrasion and abfraction [16]. While erosion is often the result of exposure to acids, abrasion is caused by the use of inappropriate dentifrice and abfraction by mechanical stresses induced by brushing and chewing. The problem is further complicated by exposure to a wide range of temperatures, chemical compositions and $\mathrm{pH}$ values during intake of food. The notches serve as very effective stress raisers and are often the sites of failure due to fracture. While cusp fractures are common in posterior teeth, the anterior teeth are more susceptible to fracture at the gingiva, severing the crown of the tooth. Although such fractures have not been studied extensively, it is generally believed that tooth failure is associated either with catastrophic events induced by very high occlusal stresses or, more plausibly, by cyclic fatigue-induced subcritical crack growth. In view of this possibility, it is perhaps surprising that so few studies have investigated the effect of prolonged fatigue cycling on human dentin, particularly as such information is 
additionally important for the development of replacement materials for restorative dentistry. To address this deficiency, the present work seeks to present an initial investigation of the response of dentin to fatigue loading in terms of both classical (stress-life) and fracturemechanics based approaches.

\section{Background}

In engineering terms, fatigue refers to the response of a material to repeated application of stress or strain. For most structures, the prediction of a time to failure under such loading conditions is a crucial step for engineering design and the assurance of durability. The classical approach to fatigue has involved the characterization of the total life to failure in terms of a cyclic stress range, and is often termed the "stress-life" or " $S / N$ " approach. This method involves the estimation of the number of cycles required to induce complete fatigue failure of a (nominally flaw-free) "smooth-bar" specimen at a given alternating $\left(\sigma_{a}\right)$ and mean $\left(\sigma_{\mathrm{m}}\right)$ stress, where the measured fatigue lifetime represents the number of the cycles both to initiate and propagate a (dominant) crack to failure. $S / N$ curves for certain materials, such as steels, can exhibit a plateau at about $10^{6}-10^{7}$ cycles, termed the fatigue limit, below which failure does not occur [17]. In the absence of a fatigue limit, a fatigue endurance strength is generally defined as the alternating stress to give a specific number of cycles to failure. Both terms are used as a basis for traditional fatigue design and life prediction, after adjustment for such operational variables as the presence of notches, the environment (e.g., temperature, $\mathrm{pH}$, humidity, etc.), the history and spectrum of loading, and so forth [17]. 
However, in many structures where there is an inherent population of flaws, including human teeth, the crack initiation life may be essentially non-existent, thus making lifetimes predicted from the $S / N$ approach highly non-conservative. In these instances, the life may be considered solely as the number of cycles to propagate one such flaw to failure. To make such predictions, a fracture mechanics methodology is generally used (termed the damagetolerant approach), where the number of cycles required for an incipient crack to grow subcritically to a critical size, defined by the limit load or fracture toughness [18], is computed from information relating the crack velocity to the mechanical driving force (e.g., the stress-intensity factor). ${ }^{1}$

\footnotetext{
${ }^{1}$ For an example of such a "damage-tolerant" life-prediction analysis in the bioengineering context, the reader is referred to the analysis of the projected life of mechanical heart valve prostheses in refs. [19,20].

The specific objective of the present study is to characterize the stress-life and crackpropagation fatigue behavior of human dentin in Hank's Balanced Salt Solution (HBSS), and to use this information as a preliminary basis to develop such lifetime prediction analyses for teeth.
}

\section{Experimental Procedures}

\subsection{Materials}

Recently extracted human molars were used in this study. Each tooth was sterilized using gamma radiation after extraction [21]. Sections, $\sim 1.5-2.0 \mathrm{~mm}$ thick, were prepared from the central portion of the crown and the root vertically through the tooth (Fig. 1). The 
typical microstructure of dentin is shown in Fig. 2, and is discussed in section 4.1. Beams of dentin, measuring approximately $0.9 \times 0.9 \times 10.0 \mathrm{~mm}$, were machined so that the long axis of the tubules was aligned along the length of the beam, perpendicular to the plane of the collagen fibrils. Samples were then obtained from these sections by wet polishing up to a 600 grit finish; twenty-five such beams were used in the present study. Each beam included some root dentin and some coronal dentin such that the loading configuration shown in Fig. 3 could be achieved. In vitro first yield $\left(\sigma_{\mathrm{y}}\right)$ and maximum flexural $\left(\sigma_{\mathrm{F}}\right)$ strengths levels were measured in Hank's Balanced Salt Solution (HBSS) in bending to be $\sigma_{\mathrm{y}} \sim 75 \mathrm{MPa}$ and $\sigma_{\mathrm{F}} \sim$ $160 \mathrm{MPa}$, respectively. It should be noted here that the "yielding" observed is the result of irrecoverable diffuse damage as observed for example, in trabecular bone [22].

\subsection{Stress-life testing}

In vitro $\mathrm{S} / \mathrm{N}$ fatigue tests were conducted in ambient temperature HBSS with unnotched cantilever beams (Fig. 3) cycled on an ELF $^{\circledR} 3200$ series acoustic testing machine (EnduraTEC Inc., Minnetonka, MN) using a Delrin ${ }^{\mathrm{TM}}$ loading rig. Testing was performed at a load ratio, $R$ (minimum load/maximum load) of 0.1 at cyclic frequencies of 2 and $20 \mathrm{~Hz}$. The dentin beams were cycled to failure under displacement control, with the loads being monitored continuously. Stress-life curves were derived for both frequencies in terms of the stress amplitude, $\sigma_{\mathrm{a}}$, (given by one half of the difference between the maximum and

minimum stresses), based on the nominal bending stress in the beam. The minimum and maximum stress levels employed ranged between, respectively, $\sim 5$ and $135 \mathrm{MPa}$, representing values of $\sim 3 \%$ and $85 \%$ of the ultimate tensile strength of dentin. 
In addition, limited stress-life testing was also performed with identical samples under sustained (non-cyclic) loads in order to distinguish whether the mechanisms of failure involve processes that are promoted by the maximum rather than the alternating stresses (i.e., static vs. cyclic fatigue). Specifically, specimens were held at a sustained stress level of 118.5 MPa, i.e., $\sim 75 \%$ of the ultimate tensile strength, similar to the maximum load used in some of the cyclic fatigue tests, and the time to failure monitored. Unbroken sustainedloaded specimens were also subsequently cycled (at $R=0.1$ at a frequency of $2 \mathrm{~Hz}$ ) at a alternating stress of $20 \mathrm{MPa}$ just below the fatigue limit in order to examine the role of crack initiation. Further details of these experiments along with the implications of the results are discussed in Section 4.4.

\subsection{Crack-propagation behavior}

Crack-propagation rates were estimated from the loss in stiffness of the test specimens during the $S / N$ fatigue tests. Since the fractography (as described in section 4.5) shows that the failure process in dentin involves the initiation and growth of a single dominant crack, continuous in situ monitoring of the specimen stiffness, measured in terms of the bending load and loadline displacement, was used to yield an estimate of the specimen compliance, which was then related to a crack size using standard beam theory and fracture mechanics analyses. This method is based on the notion that the extent of local diffuse microdamage around the crack tip is substantially smaller than all other relevant dimensions; this is akin to the assumption of small-scale yielding in linear-elastic fracture mechanics terminology.

The sample compliance was calculated using the analysis for the additional remote-point displacement, i.e., rotation $\theta_{\text {crack, }}$, due to a crack in a beam under cantilever bending [23]: 


$$
\theta_{\text {crack }}=\theta_{\text {total }}-\theta_{\text {no crack }},
$$

where $\theta_{\text {total }}$ and $\theta_{\text {no crack }}$ are, respectively, the total rotation and the rotation of an uncracked sample (of identical dimensions). These rotations can be readily calculated from standard beam theory, where $\theta_{\text {crack }}$ is given by [23]:

$$
\theta_{\text {crack }}=4 \sigma S(a / b) / E^{\prime}
$$

where $\sigma$ is the maximum nominal bending stress (in the absence of a crack), $a$ is the crack length, $b$ is the beam width, $E^{\prime}=E$, the Young's modulus, in plane stress and $E /\left(1-v^{2}\right)$ in plane strain ( $v$ is Poisson's ratio), and the function $S(a / b)$ is given by [23]:

$S(a / b)=(a / b)^{2}\left\{5.93-19.69(a / b)+37.14(a / b)^{2}-35.84(a / b)^{3}+13.12(a / b)^{4}\right\} /(1-(a / b))^{2}$.

Through continuous monitoring of this change in compliance, the crack length, $a$, and hence the crack-growth rate, $\mathrm{d} a / \mathrm{d} N$, was determined. Crack-growth rates were computed using finite-difference methods over increments of crack extension of approximately $70 \mu \mathrm{m}$.

With a knowledge of the applied loads and the crack length, the stress-intensity factor, $K$, can be determined; this parameter characterizes the magnitude of the stress and displacement fields ahead of the crack, and as such can be used to describe the linear-elastic driving force for crack advance. In the present study, stress intensities were calculated from standard handbook solutions, in terms of the applied stress range, $\Delta \sigma$, and crack size, $a[23]$ :

$$
\Delta K=\Delta \sigma(\pi a)^{1 / 2} f(a / b),
$$


where $\Delta K$ is the stress-intensity range $\left(=K_{\max }-K_{\min }\right)$, and $f(a / b)$ is a function of the specimen geometry and crack size [23,24], viz.:

$$
f(a / b)=1.122-1.40(a / b)+7.33(a / b)^{2}-13.08(a / b)^{3}+14.0(a / b)^{4} .
$$

The crack propagation results are presented as standard log-log plots of the growth rate per cycle, $\mathrm{d} a / \mathrm{d} N$, as a function of the stress-intensity range, $\Delta K$.

\subsection{Fractography}

The morphology of the fracture surfaces for both fatigue and overload fracture were examined using a standard scanning electron microscope. Surfaces were sputter-coated with a gold-palladium alloy prior to investigation. In addition, the crack paths were also examined by stopping a test specimen containing a growing fatigue crack prior to failure and examining it metallographically perpendicular to the plane of the fracture surface. To achieve this, the section of the specimen containing the crack was cold-mounted in epoxy, polished down to a 1200 grit finish, and sputter-coated prior to investigation by optical and scanning electron microscopy.

\section{Results}

\subsection{Microstructure of dentin}

Human dentin is essentially a hydrated composite composed of nanocrystalline carbonated (calcium phosphate based) apatite mineral ( $45 \%$ by volume), type-I collagen fibrils ( $\sim 30 \%$ by volume) and fluid, and other non-collageneous proteins ( $\sim 25 \%$ by volume). 
The apatite mineral is distributed in the form of fine crystallites ( $5 \mathrm{~nm}$ thick) in a scaffold created by the collagen fibrils (typically of 50-100 nm diameter). The distinctive feature of the "microstructure" of the dentin is a distribution of cylindrical tubules (typically $\sim 1-2 \mu \mathrm{m}$ in diameter) that run from the dentin-enamel junction to the interior pulp chamber (Figs. 1-2). These dentinal tubules are surrounded by a collar of highly mineralized peritubular dentin $(\sim 1 \mu \mathrm{m}$ thick) and are embedded within a matrix of mineralized collagen called intertubular dentin. The mineralized collagen fibrils form a planar felt-like structure oriented perpendicular to the tubules [25]. The tubules can be considered to be randomly displaced about a periodic lattice [26], but with a distribution that depends on location within the tooth [e.g., 14]. There is evidence, although somewhat inconclusive, that the orientation of the tubules leads to anisotropic mechanical properties in human dentin [e.g., 5,6,12]. Similar directional anisotropy has been reported for other biological tissues, e.g. bone [e.g., 27]. The present study, however, is restricted to a single orientation with cracking nominally perpendicular to the long axis of the tubules, i.e., in the plane of the collagen fibrils. This orientation is believed to have the lowest fracture toughness properties $[5,6,8,19]$.

\subsection{Stress-life behavior}

Stress-life data, obtained at cyclic frequencies of 2 and $20 \mathrm{~Hz}$ with $R=0.1$, are shown in Fig. 4 and Table I in the form of the number of fatigue cycles to failure, $N_{\mathrm{f}}$, as a function of the applied stress amplitude, $\sigma_{\mathrm{a}}$; results are compared with corresponding behavior under sustained loading. Each reported lifetime is from a single specimen. Cyclic fatigue data spanning about five decades in life, from $10^{2}-10^{3}$ to $10^{6}-10^{7}$ cycles, were obtained. It is evident that dentin shows "metal-like" fatigue behavior in that fatigue lifetimes increase with 
decreasing stress amplitudes until an apparent plateau, resembling a fatigue limit, is reached at $\sim 10^{6}$ cycles. Values for this apparent fatigue limit in dentin ranged from $25 \mathrm{MPa}$ at $2 \mathrm{~Hz}$ to $45 \mathrm{MPa}$ at $20 \mathrm{~Hz}$, representing values of $\sim 15$ to $30 \%$ of the measured tensile strength; this is to be compared with most metallic materials where, at this load ratio, the fatigue limit is typically 25 to $30 \%$ of the tensile strength.

Table I: Stress-life and stress-time data for fatigue and sustained-load cracking (SLC) in human dentin

\begin{tabular}{cccc}
\hline $\begin{array}{c}\text { Stress Amplitude } \\
\sigma_{\mathrm{a}}(\mathrm{MPa})\end{array}$ & $\begin{array}{c}\text { Cycles to Failure } \\
N_{\mathrm{f}}\end{array}$ & $\begin{array}{c}\text { Maximum Stress } \\
\sigma_{\max }(\mathrm{MPa})\end{array}$ & $\begin{array}{c}\text { Time to Failure } \\
t_{\mathrm{f}}(\mathrm{s})\end{array}$ \\
\hline $2 \mathrm{~Hz}:$ & & & \\
63.3 & $1.30 \times 10^{3}$ & 139.0 & $6.50 \times 10^{2}$ \\
53.9 & $4.30 \times 10^{3}$ & 118.5 & $2.15 \times 10^{3}$ \\
53.3 & $4.00 \times 10^{3}$ & 118.5 & $2.00 \times 10^{3 *}$ \\
51.9 & $5.16 \times 10^{3}$ & 118.0 & $2.00 \times 10^{3}$ \\
48.9 & $1.12 \times 10^{4}$ & 108.6 & $2.56 \times 10^{3}$ \\
42.6 & $5.41 \times 10^{4}$ & 97.5 & $2.70 \times 10^{4}$ \\
34.1 & $1.35 \times 10^{5}$ & 75.7 & $6.75 \times 10^{4}$ \\
32.7 & $2.22 \times 10^{5}$ & 72.7 & $1.11 \times 10^{5}$ \\
30.5 & $2.35 \times 10^{5}$ & 70.8 & $1.18 \times 10^{5}$ \\
25.2 & $>1.54 \times 10^{6}$ & 56.0 & $>7.70 \times 10^{5 *}$ \\
\hline 20 Hz: & & & \\
60.7 & $6.10 \times 10^{3}$ & 135.4 & $3.05 \times 10^{2}$ \\
51.3 & $1.51 \times 10^{4}$ & 109.7 & $7.56 \times 10^{2}$ \\
51.7 & $2.60 \times 10^{4}$ & 114.8 & $1.30 \times 10^{3}$ \\
44.9 & $>1.20 \times 10^{6}$ & 99.7 & $>6.00 \times 10^{4 *}$ \\
45.7 & $>1.29 \times 10^{6}$ & 101.2 & $>6.45 \times 10^{4 *}$ \\
42.5 & $>10.0 \times 10^{6}$ & 97.5 & $>5.00 \times 10^{5 *}$ \\
38.5 & $>3.72 \times 10^{6}$ & 88.3 & $>1.86 \times 10^{5 *}$ \\
\hline SLC Test B (see Fig. 5): & & & \\
0 & - & 118.5 & $>2.38 \times 10^{5 *}$ \\
SLC Test C (see Fig. 5): & $>1.72 \times 10^{6}$ & & \\
20 & & 44.4 & $>8.59 \times 10^{5 *}$ \\
\hline
\end{tabular}

"Test A (see Fig. 5)

*Specimen did not fail 
There is a marked effect of cyclic frequency on the stress-life fatigue behavior of human dentin, with substantially longer lifetimes at the higher frequency. This effect has been observed in many systems, e.g., in human bone [28], bone cement [e.g., 29] and many metallic materials [e.g., 17], and is generally attributed either to a time-dependent contribution to cracking (e.g., at lower frequencies, the crack is open for a long time period, thus permitting environmentally-assisted cracking mechanisms to be more active) or in rarer cases to strain-rate effects [e.g., 17]. If the data in Fig. 4 are re-plotted on the basis of time rather than cycles, where the maximum applied stress, $\sigma_{\max }$, is plotted as a function of the time-to-failure, $t_{\mathrm{f}}$, (Fig. 5), the effect of testing frequency is significantly diminished, indicating that the mechanisms of fatigue-related failures in dentin may be predominantly time, rather than cycle, dependent. Similar behavior has previously been reported in human bone [28].

\subsection{Crack path and fractographic observations}

The fractography of fatigue and overload (fast fracture) failures in human dentin is shown in the scanning electron micrographs in Figs. 6-8. A low magnification view of the entire fracture surface of a cyclic fatigue sample, shown in Fig. 6, indicates that crack initiation occurred at the top surface of the sample (between the two white arrows), where the tensile stress is at a maximum. Subsequent fatigue-crack growth was relatively free of tortuosity and occurred in a plane perpendicular to the long axis of the tubules. Higher magnification images of the fatigue region in Fig. 7 reveal little evidence of a marked effect of the tubules in influencing the crack-advance process (as might be seen, for example, by cavitation or the "bowing" of the crack front around the tubules), although there may be some degree of 
pullout of the peritubular dentin cuffs surrounding the tubules (as indicated by the arrows in Figs. 7-8), which might contribute to the crack-growth resistance. However, there was no evidence of fatigue striations, which are indicative of an incremental crack-growth process resulting from alternating plastic blunting and sharpening at the crack tip; this process represents the most common fatigue mechanism in ductile materials, such as many metals and polymers [17], but is apparently not operating in human dentin.

Fracture surfaces representative of the overload failure are shown in Fig. 8. As reported previously [30], few differences exist between the morphology of these fractures and those associated with cyclic fatigue-crack growth (Fig. 7), although macroscopically the overload fracture surfaces are somewhat rougher. Such behavior is more indicative of brittle materials, such as many ceramics and pyrolytic carbon [30,31], where the mechanisms of crack advance (and hence the fractography) are essentially identical under cyclic and overload conditions; the fatigue effect in these materials is more commonly associated with mechanisms behind the crack tip involving the progressive degradation of the operative crack-tip shielding (extrinsic toughening) processes [32]. Furthermore, there were no observable differences in the appearance of the fracture surfaces at $2 \mathrm{~Hz}$ and $20 \mathrm{~Hz}$.

A typical scanning electron micrograph of the crack profile is included in Fig. 9. As is evident, there is very little tortuosity in the path that the fatigue crack follows, indicating that the tubule-based microstructure does not appear to significantly influence the propagation of the crack and hence contribute to the toughness or fatigue resistance. However, there is some evidence of pull-out of the peritubular dentin cuff inside the crack, as indicated by the white arrows in the figure, which may be indicative of a small contribution to the crack-growth resistance. 


\subsection{Sustained-load cracking behavior}

It is evident from the fatigue results in Fig. 5 that plotting with respect to time provides a somewhat better representation of the data. This raises the possibility that the primary mechanism of subcritical crack growth in dentin is time, rather than cycle, dependent. Such sustained-load cracking (SLC) mechanisms are often environmentally-assisted, e.g., stresscorrosion cracking, and are commonly encountered in the fatigue of brittle materials where the cycle-dependent mechanisms are less prevalent. Indeed, it is well known that fatigue lifetimes can be predicted from static fatigue data for such materials, in the absence of any cycle-dependent mechanisms $[33,34]$. Using this analysis in reverse, which equates the role of static and cyclic loads by integrating over the fatigue loading cycle, the time to failure under static loading, $t_{\mathrm{s}}$, can related to the corresponding time to failure under cyclic loads, $t_{\mathrm{c}}$, in terms of the relative magnitudes of the stress amplitude, $\sigma_{\mathrm{a}}$, in the fatigue test and the corresponding maximum stress, $\sigma_{\mathrm{s}}$, in the static test [33]:

$$
t_{\mathrm{s}} / t_{\mathrm{c}}=g\left(\sigma_{\mathrm{a}} / \sigma_{\mathrm{s}}\right)^{n}
$$

where $n$ is an environment- and temperature-dependent system constant (typically 15 to 60) and $g$ is the time-to-failure ratio (from [33]). Using results at a stress level of $118.5 \mathrm{MPa}$, representing the maximum stress corresponding to a fatigue stress amplitude of $\sigma_{\mathrm{a}}=53.3$ MPa where the experimentally measured fatigue lifetime was 4,000 cycles at $2 \mathrm{~Hz}$ (Fig. 5), Eq. 6 implies that the time to failure under static loads should be in the range of 180 to $460 \mathrm{~s}$. However, experimentally, no failures were observed even after $\sim 2.4 \times 10^{5} \mathrm{~s}$ at a sustained load of 118.5 MPa. There are several explanations for this apparent inconsistency: (i) there are both time- and cycle-dependent mechanisms that are active during the fatigue of dentin in 
physiological environments (which is very likely), and (ii) crack initiation occurs much more readily under cyclic loading. To examine this latter point further, one specimen tested under sustained loading was subsequently fatigue cycled at $20 \mathrm{MPa}$, just below the fatigue limit (at $R=0.1$ with $2 \mathrm{~Hz}$ frequency). Once again, no failure was observed even after over $1.72 \mathrm{x}$ $10^{6}$ cycles $\left(\sim 8.6 \times 10^{5} \mathrm{~s}\right)$. This experiment implies that a crack had not initiated under sustained loading even after more than $10^{5} \mathrm{~s}$ at a load level at which under cyclic loading, failure would have ensued in less than $2000 \mathrm{~s}$. This strongly suggests that the process of crack initiation in human dentin is far more difficult under sustained loading, compared to that under corresponding cyclic loads. Similar behavior is observed in many lower strength metallic materials, where the thresholds for subcritical cracking are much lower in cyclic loading than under sustained loads [e.g., 35].

\subsection{Fatigue-crack propagation behavior}

To the authors' knowledge, there are no reports to date of fatigue-crack propagation behavior for human dentin in archival literature. In the present study, such data were derived from continuous in situ measurements of the stiffness loss during the $S / N$ fatigue tests; typical plots of the drop in maximum load, at constant displacement, in the fatigue cycle with number of cycles are shown in Fig. 10. It is apparent that the decay in stiffness is relatively minor until the latter stages of the test, indicating that, similar to many materials, the majority of the fatigue lifetime is spent in initiating a small propagating crack (in this instance, typically on the order of $100-150 \mu \mathrm{m})$.

Using the procedures described in section 3.3 to estimate the crack lengths, stressintensity levels and crack-growth rates, a plot of the variation in $\mathrm{d} a / \mathrm{d} N$ with the stress- 
intensity range $\Delta K$ was derived. Results are shown in Fig. 11 and are believed to be the first reported fatigue-crack growth rate data for human dentin. In common with many materials [17], the variation in growth rates with $\Delta K$ in dentin can be described by a simple Paris power-law relationship:

$$
\mathrm{d} a / \mathrm{d} N=C(\Delta K)^{\mathrm{m}}=6.24 \times 10^{-11}(\Delta K)^{8.76}
$$

where $C$ and $m$ are scaling constants, with their values quoted for units of $\mathrm{MPa} \sqrt{\mathrm{m}}$ (on $\Delta K$ ) and $\mathrm{m} /$ cycle (on $\mathrm{d} a / \mathrm{d} N$ ). This behavior is consistent with that observed for many brittle materials, which generally have far higher Paris exponents than the $m$ values of $\sim 2$ to 4 that are generally reported for ductile (e.g., metallic) materials [32]. The exponent of $\sim 8.76$ found for dentin is somewhat smaller than that reported for apatite bone mineral substitute (where $m \sim 17)[36]$.

When characterizing the fatigue-crack growth properties of a material, it is often useful to define a threshold stress intensity, $\Delta K_{\mathrm{TH}}$ or $K_{\mathrm{max}, \mathrm{TH}}$, below which crack growth is dormant or proceeds at vanishingly low rates; this parameter can be operationally defined as the stress intensity corresponding to an average growth rate of $10^{-10} \mathrm{~m} / \mathrm{cycle}$. Extrapolating the current results to this lower bound yields an approximate threshold $\Delta K_{\mathrm{TH}}$ for human dentin of 1.06 $\mathrm{MPa} \sqrt{\mathrm{m}}$. This value is roughly $60 \%$ of the measured fracture toughness $\left(K_{\mathrm{c}} \sim 1.8 \mathrm{MPa} \sqrt{\mathrm{m}}\right.$ [18]), and is typical of many brittle materials where $\Delta K_{\mathrm{TH}} \sim 0.4-0.6 K_{\mathrm{c}}$ [32]. By comparison, fatigue thresholds for other common brittle materials are in the same range: $\Delta K_{\mathrm{TH}} \sim 2.5$ $\mathrm{MPa} \sqrt{\mathrm{m}}$ for cortical bone $[35,36]^{2}, \sim 1$ to $4 \mathrm{MPa} \sqrt{\mathrm{m}}$ for alumina (depending upon the grain size) [32], and $\sim 0.6$ to $0.8 \mathrm{MPa} \sqrt{\mathrm{m}}$ for pyrolytic carbon [31]. 
${ }^{2}$ It should be noted that the threshold of $2.5 \mathrm{MPa} \sqrt{\mathrm{m}}_{\mathrm{m}}$, reported in ref. [36], was taken from the data for adult bovine bone described in ref. [37]. However, as no attempt was made to actually measure the threshold in ref. [37] and the growth rates reported are no lower than $10^{-7}-10^{-6} \mathrm{~m} / \mathrm{cycle}$, it is likely that the actual threshold for this material is significantly lower than the result quoted in ref. [36].

\section{Discussion}

Typical masticatory stress levels that a human tooth experiences have been estimated to be on the order of $20 \mathrm{MPa}$ [e.g., 38]. Although these stresses are generally due to compressive loading, at these levels, a measured fatigue threshold for dentin of $\sim 1 \mathrm{MPa} \sqrt{\mathrm{m}}$ implies that any cracks formed in teeth would need to be of dimensions in the hundreds of micrometers before meaningful subcritical crack growth can occur.

With the availability of the growth-rate data for dentin shown in Fig. 11, it is now possible to make a preliminary attempt to develop conservative estimates of the expected fatigue life of teeth containing flaws of specific dimensions. This "lifing" procedure uses a worst-case fracture mechanics approach that is based on the notion that the lifetime is comprised of the time or number of loading cycles for the largest pre-existing flaw to propagate to a critical size where catastrophic failure occurs. This is achieved by integrating the Paris crack-growth relationship (Eq. 7) between the limits of the initial flaw size, $a_{0}$, and the critical (final) flaw size, $a_{\mathrm{c}}$, for failure. The latter limit can be estimated by equating the stress intensity developed ahead of the crack tip to the fracture toughness, $K_{\mathrm{c}}$ :

$$
K=f(a / b) \sigma_{\text {app }}\left(\pi a_{\mathrm{c}}\right)^{1 / 2}=K_{\mathrm{c}},
$$


where $\sigma_{\text {app }}$ is the in-service stress, $f(a / b)$ is a function dependent upon the geometry, flaw size and shape, and $K_{\mathrm{c}}$ for dentin is $\sim 1.8 \mathrm{MPa} \sqrt{\mathrm{m}}$ [18]. The number of loading cycles to cause failure is thus a strong function of the in-service stress and initial flaw size, and can be expressed (for $m \neq 2$ ) as:

$$
N_{\mathrm{f}}=\frac{2}{(m-2) C}\left(f(a / b) \Delta \sigma_{\mathrm{app}}\right)^{-m} \pi^{-m / 2}\left[a_{\mathrm{o}}^{1-m / 2}-a_{\mathrm{c}}{ }^{1-m / 2}\right],
$$

thereby providing a conservative basis for the prediction of the life of a tooth. Since the scaling constants $C$ and $m$ are set by the crack-growth relationship for dentin in Eq. 7, and we can reasonably assume masticatory stress levels of $\sim 20 \mathrm{MPa}$ [38], the principal factor that needs to be defined is the function $f(a / b)$, which is usually of the order of unity but depends specifically on the size and shape of the flaw and its configuration within the tooth.

As an illustration of this approach, we can assume the presence of a semi-elliptical surface flaw small compared to the dimensions of the tooth. For shallow cracks in this configuration, $f(a / b)=1.12 / \sqrt{ } \Phi$, where $\Phi$ is the so-called shape factor (an elliptic integral of the second kind that depends upon the shape of the flaw and the level of stress in relation to the flow stress) [39]. Since the in-service stresses are generally small $\left(\sigma_{\text {app }} / \sigma_{\text {uts }} \sim 0.12\right)$, a worst-case value for $\Phi$ for a shallow crack can be taken as 1 . Using this configuration for Eq. 9, predictions of the life as a function of the initial flaw size are shown in Fig. 12 for a range of in-service stress levels. As noted above, because of the moderately high Paris exponent $(m \sim 8.76)$ in dentin (as compared to most metallic alloys), projected lives are a very strong function of initial flaw size. Specifically, for an initial flaw of $\sim 100 \mu \mathrm{m}$ in size, the predicted fatigue lifetime at a worst-case stress of $20 \mathrm{MPa}$ is well over a billion cycles. 
On the assumption that a human tooth is subjected to something on the order of a million cycles per year [40], the fatigue life of the tooth would be infinite. However, for a larger flaw of $600 \mu \mathrm{m}$ in size, the projected life drops to $\sim 3.6$ million cycles, or 3 to 4 years; for a $900 \mu \mathrm{m}$ flaw, the projected life is as low as a few months. One implication of this is that any dental reconstruction process that leaves, for example, a millimeter-sized flaw, would mean that the residual lifetime of the tooth could be as short as several weeks, thus necessitating immediate repair.

It should be noted here that this simple fracture mechanics analysis is presented merely as an illustration of how life prediction could be performed for human teeth. Precise calculations would need to entail specific configurations of flaws and better estimates of the in vivo stresses and stress-states. We believe, however, that this approach is inherently more reliable than the traditional stress-life approach, which would not have predicted any failures for the physiological stresses of $20 \mathrm{MPa}$. (This is because the $S / N$ approach does not assume the presence of pre-existing flaws, and that $20 \mathrm{MPa}$ is apparently below the relevant endurance strength for dentin (Fig. 4)). However, we have not considered several factors that may affect fatigue behavior in human dentin. These include the magnitude and physiological loading history of the tooth, most especially the presence of occasional "over-stresses" (in fact, much higher stress levels have been reported for some masticatory processes [38]), the presence of mixed-mode (tensile/compressive plus shear) loads, the physical nature of the flaws, the effect of orientation (if any) on the crack-growth rates, and the occurrence of possible long-term environmental effects on fatigue due to corrosive and bacterial fluids inside the mouth. Because of these uncertainties in the precise loading and crack size/shape configurations, these predictions must only be considered as a rough indication of the life of 
the tooth. However, they do indicate the general trend that for typical physiological stresses of 5 to $20 \mathrm{MPa}$, small flaws in teeth of the order of $250 \mu \mathrm{m}$ will not radically affect their structural integrity, as predicted fatigue lifetimes will exceed the life of the patient.

\section{Conclusions}

Based on the in vitro study of the fatigue properties of human dentin, involving both stress/life and crack-propagation behavior in ambient temperature Hank's Balanced Salt Solution, the following conclusions can be drawn:

1. The existence of a fatigue response to repetitive loading in human dentin tested in vitro has been demonstrated.

2. Attempts to discern whether the observed fatigue behavior in dentin was either cycleand/or time-dependent, using a comparison of cyclic fatigue and sustained-load tests, were inconclusive, although it appeared that both cycle- and time-dependent mechanisms were involved. Crack initiation, however, occurred far more readily under cyclic loading.

3. "Smooth-bar" stress-life $(S / N)$ behavior for dentin was observed to exhibit "metal-like" character with decreasing fatigue lives associated with increasing stress amplitude. $S / N$ curves (at a load ratio of $R=0.1$ ) displayed an apparent fatigue limit at $10^{6}-10^{7}$ cycles, which was estimated to be $\sim 25$ and $45 \mathrm{MPa}$, i.e., $\sim 15$ to $30 \%$ of the tensile strength, for cyclic frequencies of 2 and $20 \mathrm{~Hz}$, respectively.

4. Akin to many brittle materials, the morphology of the fracture surfaces created during fatigue-crack propagation was essentially identical to those created during overload (catastrophic) failure. 
5. Using a stiffness-loss technique, fatigue-crack growth rates, $\mathrm{d} a / \mathrm{d} N$, for human dentin were determined from the $S / N$ results and related to the stress-intensity range, $\Delta K$. Resulting $\mathrm{d} a / \mathrm{d} N$ vs. $\Delta K$ plots suggested a simple Paris power-law relationship, $\mathrm{d} a / \mathrm{d} N \propto$ $\Delta K^{m}$, with $m \sim 8.76$. Extrapolation to $\sim 10^{-10} \mathrm{~m} /$ cycle yielded an estimate of the fatigue threshold of $\Delta K_{\mathrm{TH}} \sim 1.06 \mathrm{MPa} \sqrt{\mathrm{m}}$, i.e., $\sim 60 \%$ of the fracture toughness, $K_{\mathrm{c}}$, of dentin.

6. A framework for a fracture-mechanics based life-prediction methodology for the fatigue life of teeth was developed, and projected lifetimes as a function of the size of preexisting flaws presented. Based on this preliminary analysis, it is concluded that under simulated physiological conditions, small flaws in teeth of the order of $250 \mu \mathrm{m}$ will not radically affect their structural integrity, as predicted fatigue lifetimes will exceed that of the patient.

\section{Acknowledgments}

This work was supported in part by the National Institutes of Health, National Institute of Dental and Craniofacial Research under Grant No. P01DE09859. The authors wish to thank Ms. G. Nonomura for assistance with specimen preparation Mr. C. L. Muhlstein for helpful discussions, and EnduraTEC Inc., Minnetonka, MN for the use of their ELF ${ }^{\circledR} 3200$ Series testing machine. 


\section{References}

1. Craig RG, Peyton FA. Elastic and mechanical properties of human dentin. J Dent Res 1958;37:710-718.

2. Lehman ML. Tensile strength of human dentin. J Dent Res 1967;46:197-201.

3. Cooper WE, Smith DC. Determination of shear strength of enamel and dentin. J Dent Res 1968;47:997p.

4. Renson CE, Boyde A, Jones SJ. Scanning electron microscopy of human dentin specimens fractured in bend and torsion tests. Arch Oral Biol 1974;19:447-457.

5. Rasmussen ST, Patchin RE, Scott DB, Heuer AH. Fracture properties of human enamel and dentin. J Dent Res 1976;55:154-164.

6. Rasmussen ST, Patchin RE. Fracture properties of human enamel and dentin in an aqueous environment. J Dent Res 1984;63:1362-1368.

7. Pashley DA, Parham P. The relationship between dentin microhardness and tubule density. Endodontics Dent Traumatology 1985;1:176 -179.

8. el Mowafy OM, Watts DC. Fracture toughness of human dentin. J Dent Res 1986;65:677-681.

9. Goodis HE, Marshall GW, White JM, Gee L, Hornberger B, Marshall SJ. Storage effects on dentin permeability and shear bond strengths. Dent Mater 1993;9:79-84.

10. Sano H, Ciucchi B, Matthews WG, Pashley DH. Tensile properties of mineralized and demineralized human and bovine dentin. J Dent Res 1994;73:1205-1211.

11. Kinney JH, Balooch M, Marshall SJ, Marshall GW, Weihs TP. Hardness and young's modulus of human peritubular and intertubular dentin. Arch Oral Biol 1996;41:9-13.

12. Watanabe L, Marshall SJ, Marshall GW. Dentin shear strength: Effects of tubule orientation and intratooth location. Dent Mater 1996;12:109-115.

13. Balooch M, Wu-Magidi IC, Balazs A, Lundkvist AS, Marshall SJ, Marshall GW, Brekhaus WJ, Kinney JH. Viscoelastic properties of dimineralized human dentin measured in water with atomic force microscope (AFM)-based indentation. J Biomed Mater Res 1998;40:539-544.

14. Povolo F, Hermida EB. Measurement of the elastic modulus of dental pieces. J Alloys Compounds 2000;310:392-395.

15. Balooch M, Demos SG, Kinney JH, Marshall GW, Balooch G, Marshall SJ. Local mechanical and optical properties of normal and transparent root dentin. J Mater Sci: Mater Medicine 2001;12:507-514. 
16. Levitch LC, Bader JD, Shugars DA, Heymann HO. Non-carious cervical lesions. J Dent Res 1994;22:195-207.

17. Suresh S. Fatigue of materials. $2^{\text {nd }}$ ed. Cambridge, U.K.: Cambridge University Press; 1998.

18. Imbeni V, Nalla RK, Bosi C, Kinney JH, Ritchie RO. On the in vitro fracture toughness of human dentin. J Biomed Mater Res 2002; in review.

19. Lubock P, Ritchie RO. Fatigue life estimation procedures for the endurance of a cardiac valve prosthesis: Stress/life and damage-tolerant analyses. J Biomech Eng 1986;108:153160.

20. Ritchie RO. Fatigue and fracture of pyrolytic carbon: A damage- tolerant approach to structural integrity and life prediction in "ceramic" heart valve prostheses. J Heart Valve Dis 1996;5 (Suppl. 1):S9-31.

21. White JM, Goodis HE, Marshall SJ, Marshall GW. Sterilization of teeth by gamma radiation. J Dent Res 1994;73:1560-1567.

22. Vashishth D, Koontz J, Qiu S, Lundin-Cannon D, Yeni Y, Schaffler M, Fyhrie D. In vivo diffuse damage in human vertebral trabecular bone. Bone 2000;26:147-152.

23. Tada H, Paris PC, Irwin GR. $3^{\text {rd }}$ ed. The stress analysis of cracks handbook. New York, NY: ASME Press; 2000.

24. Brown WF, Srawley JE. Fracture toughness testing. In: Fracture toughness testing and its applications, ASTM STP 381. West Conshohocken, PA: ASTM; 1965.

25. Jones SJ, Boyde A. Ultrastructure of dentin and dentinogenesis. In: Linde, editor. Dentin and dentinogenesis. Boca Raton, FL: CRC Press; 1984. 1(of 2):p 81-134.

26. Kinney JH, Oliveira J, Haupt DL, Marshall GW, Marshall SJ. The spatial arrangement of tubules in human dentin. J Mater Sci: Mater Medicine 2001;12:743-751.

27. Lucksanasombool P, Higgs WAJ, Higgs RJED, Swain MV. Fracture toughness of bovine bone: influence of orientation and storage media. Biomater 2001;22:3127-3132.

28. Zioupos P, Currey JD, Casinos A. Tensile fatigue in bone: Are cycles-, or time to failure, or both important? J Theor Biol 2001;210:389-399.

29. Ishihara S, Mcevily AJ, Goshima T, Kanekasu K, Nara T. On fatigue lifetimes and fatigue crack growth behavior of bone cement. J Mater Sci: Mater Med 2000;11:661-666.

30. Ritchie RO, Dauskardt RH, Pennisi FJ. On the fractography of overload, stress corrosion and cyclic fatigue failures in pyrolytic-carbon materials used in prosthetic heart-valve devices. J Biomed Mater Res 1992;26:69-76. 
31. Dauskardt RH, Ritchie RO, Takemoto JK, Brendzel AM. Cyclic fatigue and fracture in pyrolytic carbon-coated graphite mechanical heart-valve prostheses: Role of small cracks in life prediction. J Biomed Mater Res 1994;28:791-804.

32. Ritchie RO. Mechanisms of fatigue-crack propagation in ductile and brittle solids. Int J Fract 1999;100:55-83.

33. Evans AG, Fuller ER. Crack propagation in ceramic materials under cyclic loading conditions. Metall Trans 1974;5:27-33.

34. Evans AG, Wiederhorn SM. Proof testing of ceramic materials- an analytical basis for failure prediction. Int J Fract 1974;10:379-392.

35. Suresh S, Ritchie RO. Mechanistic Dissimilarities Between Environmentally-Influenced Fatigue Crack Propagation at Near-Threshold and Higher Growth Rates in Lower Strength Steels. Metal Science 1982;16:529-538.

36. Morgan EF, Yetkinler DN, Constantz BR, Dauskardt RH. Mechanical properties of carbonated apatite bone mineral substitute: strength, fracture and fatigue behaviour. J Mater Sci: Mater Med 1997;8:559-570.

37. Wright TM, Hayes WC. The fracture mechanics of fatigue crack propagation in compact bone. J Biomed Mater Res Symn 1976;7 (J Biomed Mater Res;10):637-648.

38. Anderson DJ. Measurement of stress in mastication I. J Dent Res 1956;35:664-670.

39. Newman JC, Raju IS. An empirical stress-intensity factor equation for the surface crack. Eng Fract Mech 1981;15:185-192.

40. Schulze KA. University of California at San Francisco; private communication 2002. 


\section{List of Figure Captions}

Figure 1: Schematic illustration of a typical human tooth with the section (shown by dotted line) made for the purpose of specimen preparation. Note the tubules running from the dentin-enamel junction towards the pulp in the interior of the tooth.

Figure 2: Micrograph illustrating the typical microstructure of human dentin. The most striking feature is the pseudo-periodically placed 1-2 $\mu \mathrm{m}$ diameter tubules. The orientation of the micrograph is perpendicular to the long axis of the tubules.

Figure 3: Schematic illustration of the cantilever beam geometry used for in vitro fatigue and sustained-load stress-life testing. Each dentin beam tested included some root dentin and some coronal dentin. Testing was conducted in HBSS at ambient temperature.

Figure 4: Stress-life $(S / N)$ data for dentin in HBSS in the form of the stress amplitude, $\sigma_{a}$, as a function of the number of cycles to failure, $N_{\mathrm{f}}$. Results were obtained at frequencies of $2 \mathrm{~Hz}$ and $20 \mathrm{~Hz}$, with a load ratio of $R=0.1$. Horizontal arrows represent samples that did not fail. Inset shows the definition of the various stresses associated with the fatigue cycle.

Figure 5: Stress-time data for dentin in HBSS in the form of the maximum stress, $\sigma_{\max }$, as a function of the time to failure, $t_{\mathrm{f}}$. Results were derived from those in Fig. 4 together with the results of two sustained-load tests. Horizontal arrows represent samples that did not fail. The schematics illustrate the stress levels and sequences used for these tests.

Figure 6: Low magnification scanning electron micrograph of a failed stress-life fatigue sample, showing the probable fatigue crack initiation site (indicated by white arrows) on the top surface where the tensile stresses are at a maximum. The extension of the fatigue crack proceeds from right to left until catastrophic failure occurs.

Figure 7: Higher magnification scanning electron micrographs of the cyclic fatigue region of the fracture surface, showing evidence of pullout of the peritubular dentin cuffs (indicated by white arrows). The nominal direction of crack growth is from left to right.

Figure 8: Corresponding scanning electron micrographs of the overload fracture region of the fracture surface. Although this fracture surface is macroscopically "rougher" than that of the fatigue fracture surfaces, the morphology is essentially identical. Some evidence of pullout of the peritubular dentin cuffs (indicated by white arrows) can again be seen. The nominal direction of crack growth is from left to right. 
Figure 9: Scanning electron micrograph of a typical crack path of a fatigue crack through the dentin microstructure. Note the small degree of pullout of the peritubular dentin as indicated by the white arrows inside the crack.

Figure 10: Typical stiffness-loss data obtained during a stress-life test, showing the drop in maximum load at constant displacement as a function of the number of loading cycles. (a) The stiffness is relatively constant for the majority of the test, until (b) it drops significantly near the end. This implies that the majority of the life is spent in initiating a growing crack.

Figure 11: Plot of the variation in fatigue-crack growth rates, $\mathrm{d} a / \mathrm{d} N$, with the stress-intensity range, $\Delta K$, for human dentin in HBBS at $R=0.1$. Results suggest a simple Paris power-law relationship, with an exponent of $m \sim 17$, for crack-growth behavior. The inset shows an illustration of the geometrical configuration used for these calculations.

Figure 12: Predicted fatigue lives, in terms of the number of loading cycles $N_{\mathrm{f}}$, as a function of the initial flaw size, $a_{0}$, for a range of in-service stresses based on a hypothetical fracture-mechanics life-prediction analysis for a tooth subjected to typical physiological stresses between 5-20 MPa. Time-based lifetime estimates are based on a nominal $10^{6}$ cycles per year. 


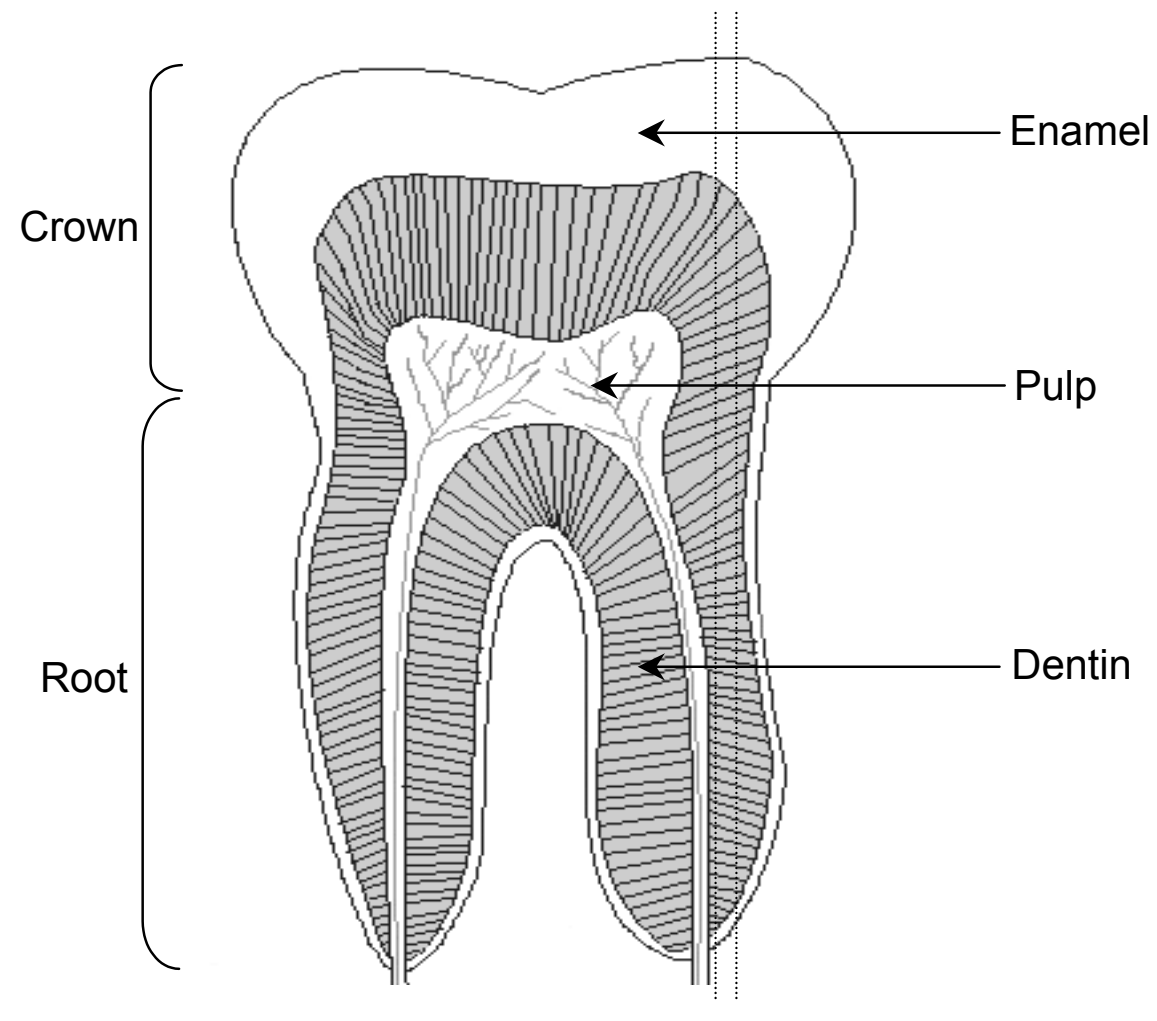

Figure 1: Schematic illustration of a typical human tooth with the section (shown by dotted line) made for the purpose of specimen preparation. Note the tubules running from the dentin-enamel junction towards the pulp in the interior of the tooth. 


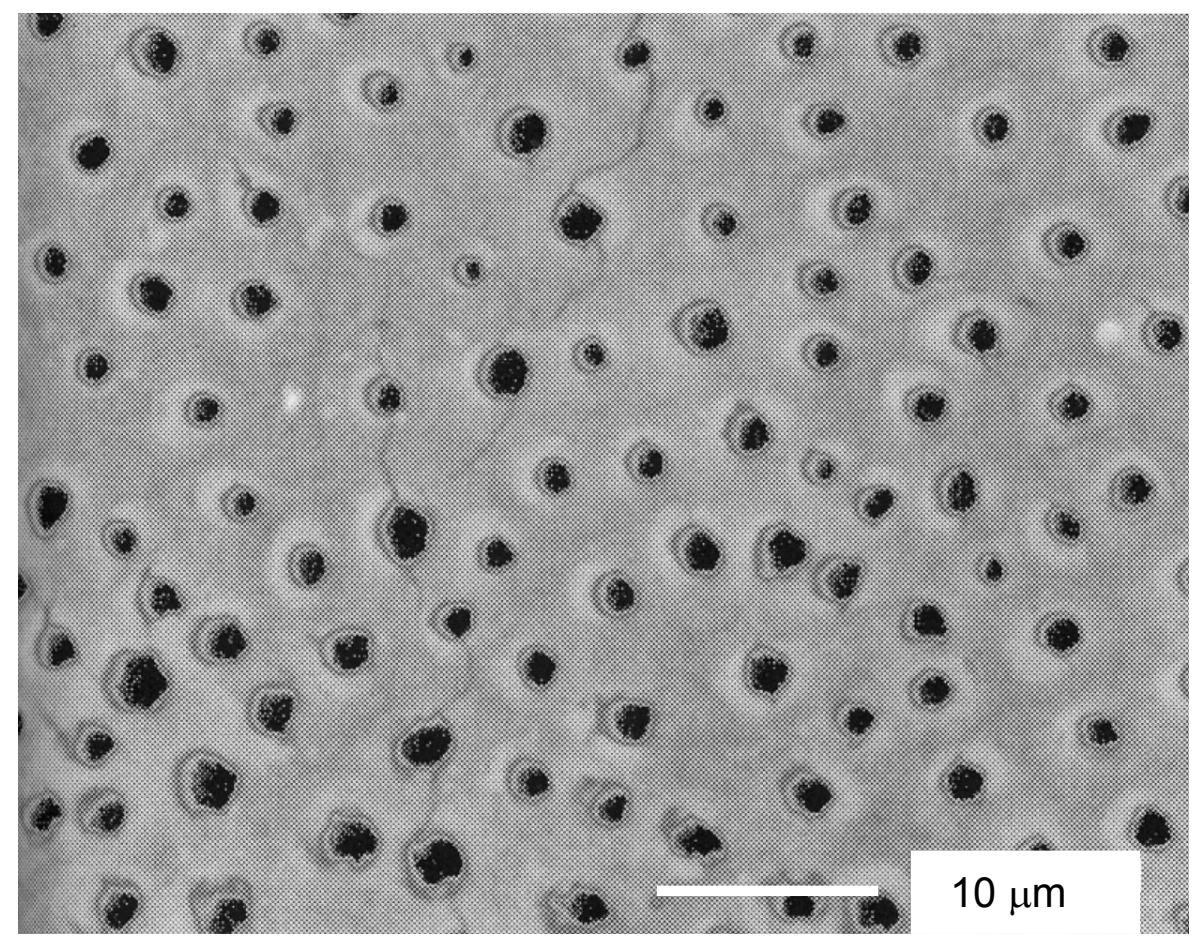

Figure 2: Micrograph illustrating the typical microstructure of human dentin. The most striking feature is the pseudo-periodically placed $1-2 \mu \mathrm{m}$ diameter tubules. The orientation of the micrograph is perpendicular to the long axis of the tubules. 


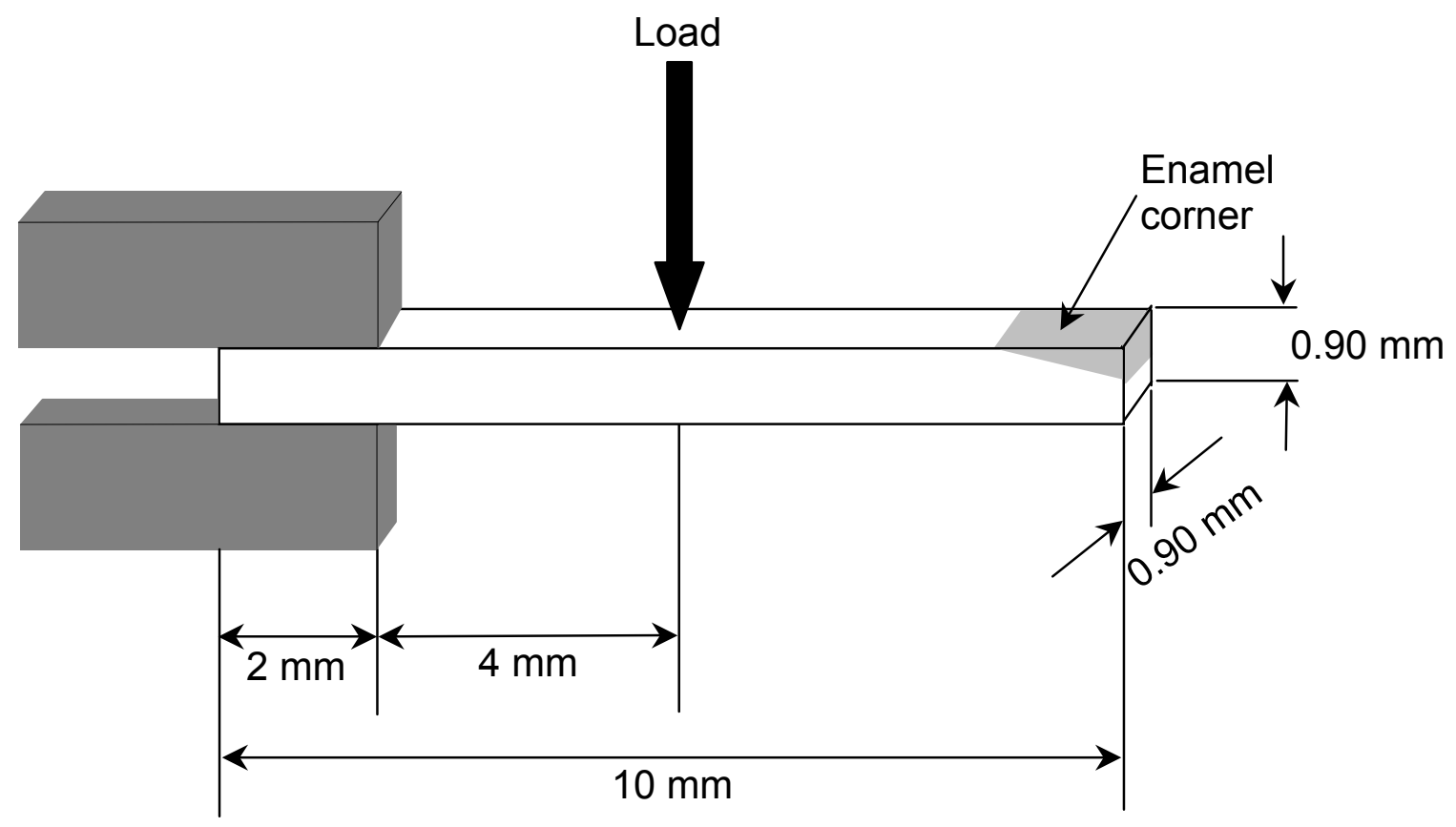

Figure 3: Schematic illustration of the cantilever beam geometry used for in vitro fatigue and sustained-load stress-life testing. Each dentin beam tested included some root dentin and some coronal dentin. Testing was conducted in HBSS at ambient temperature. 


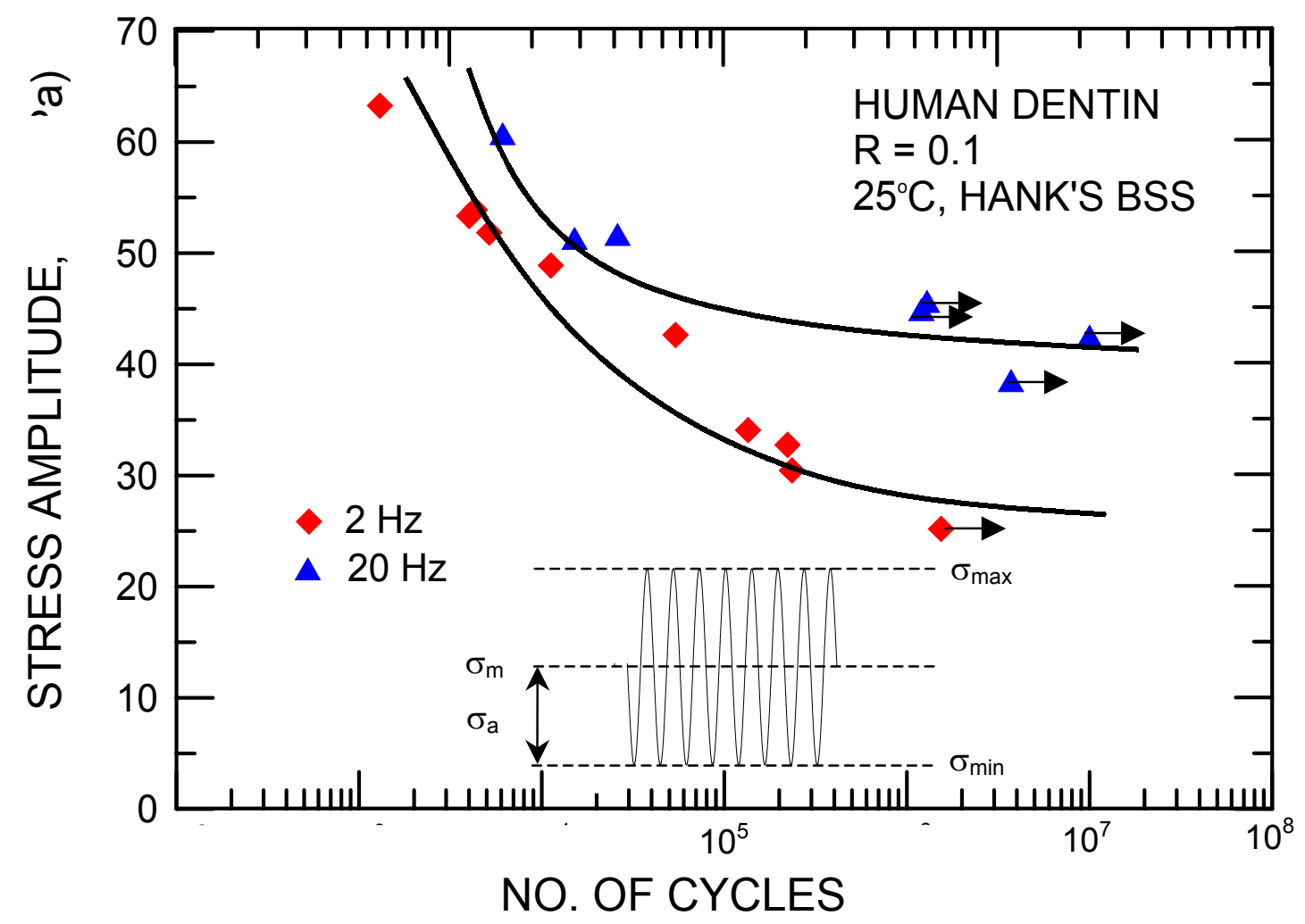

Figure 4: Stress-life $(S / N)$ data for dentin in HBSS in the form of the stress amplitude, $\sigma_{\mathrm{a}}$, as a function of the number of cycles to failure, $N_{\mathrm{f}}$. Results were obtained at frequencies of 2 $\mathrm{Hz}$ and $20 \mathrm{~Hz}$, with a load ratio of $R=0.1$. Horizontal arrows represent samples that did not fail. Inset shows the definition of the various stresses associated with the fatigue cycle. 

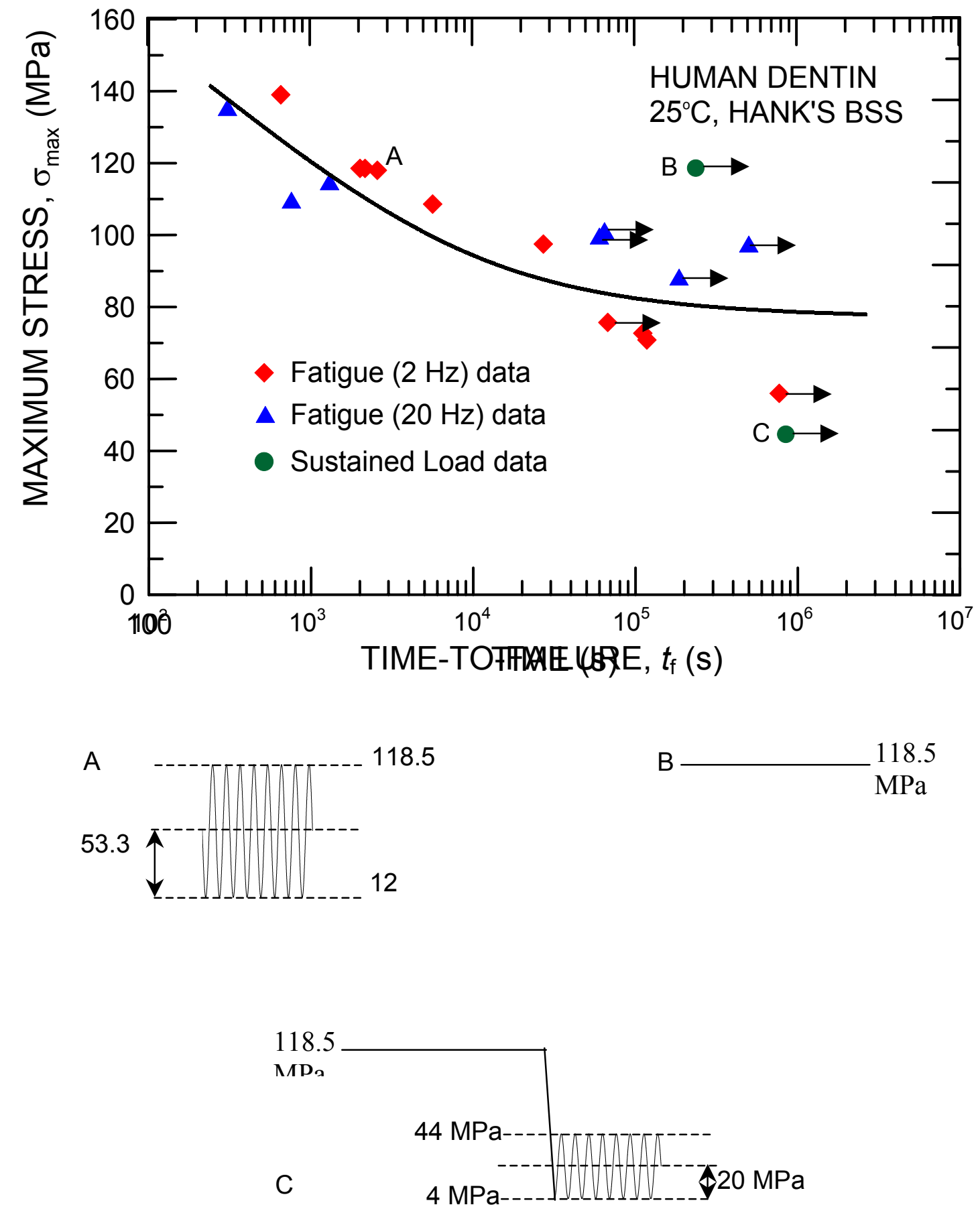

Figure 5: Stress-time data for dentin in HBSS in the form of the maximum stress, $\sigma_{\max }$, as a function of the time to failure, $t_{\mathrm{f}}$. Results were derived from those in Fig. 4 together with the results of two sustained-load tests. Horizontal arrows represent samples that did not fail. The schematics illustrate the stress levels and sequences used for these tests. 


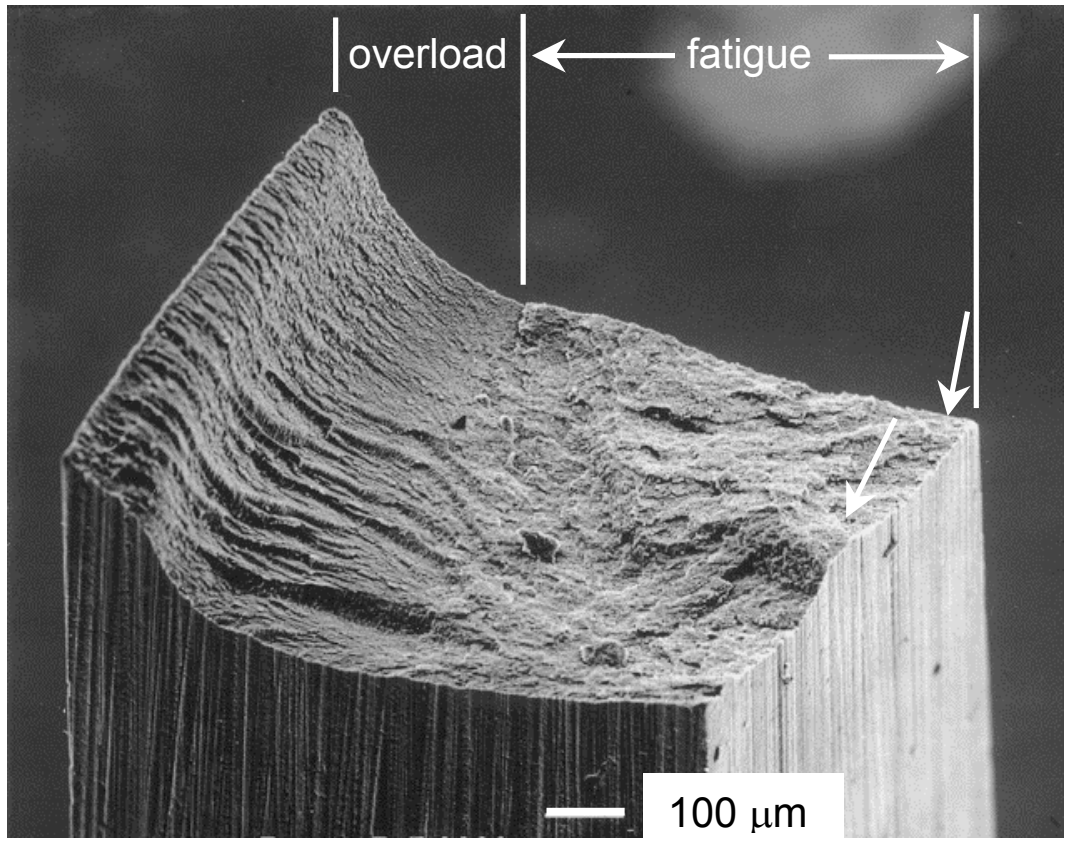

\section{Crack Growth Direction}

Figure 6: Low magnification scanning electron micrograph of a failed stress-life fatigue sample, showing the probable fatigue crack initiation site (indicated by white arrows) on the top surface where the tensile stresses are at a maximum. The extension of the fatigue crack proceeds from right to left until catastrophic failure occurs. 


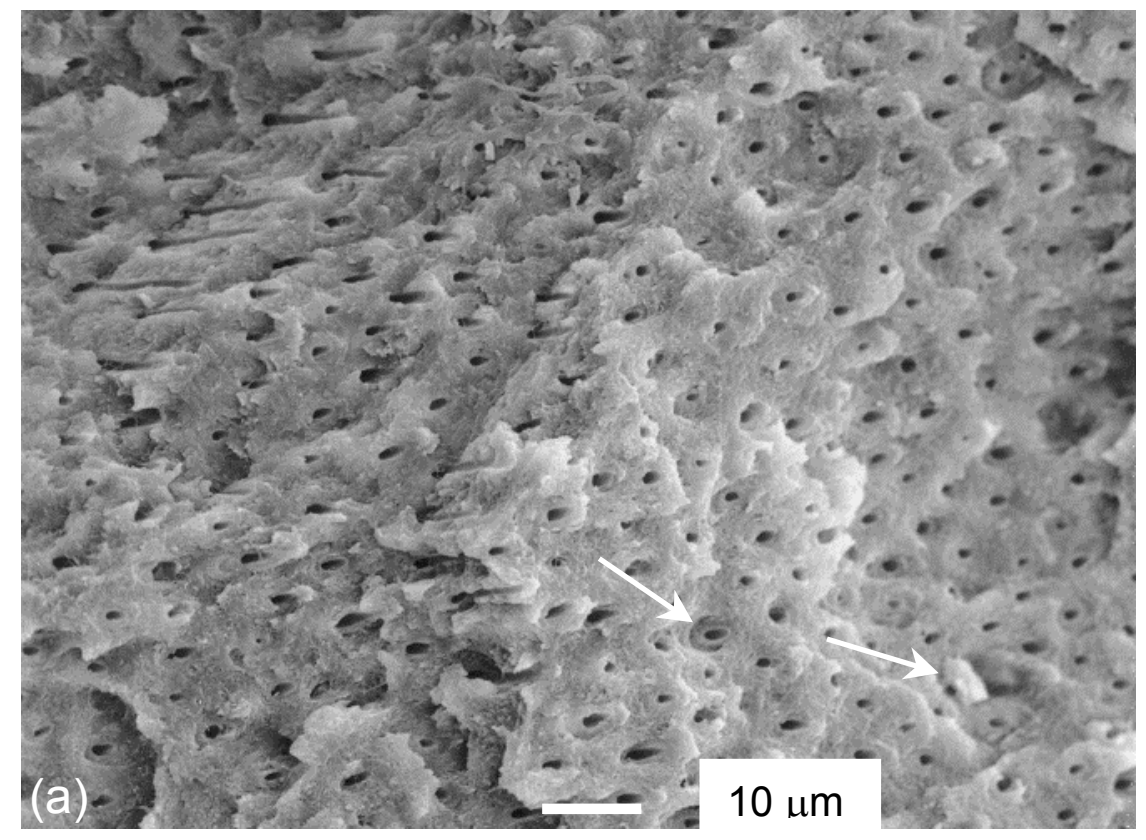

\section{Crack Growth Direction}

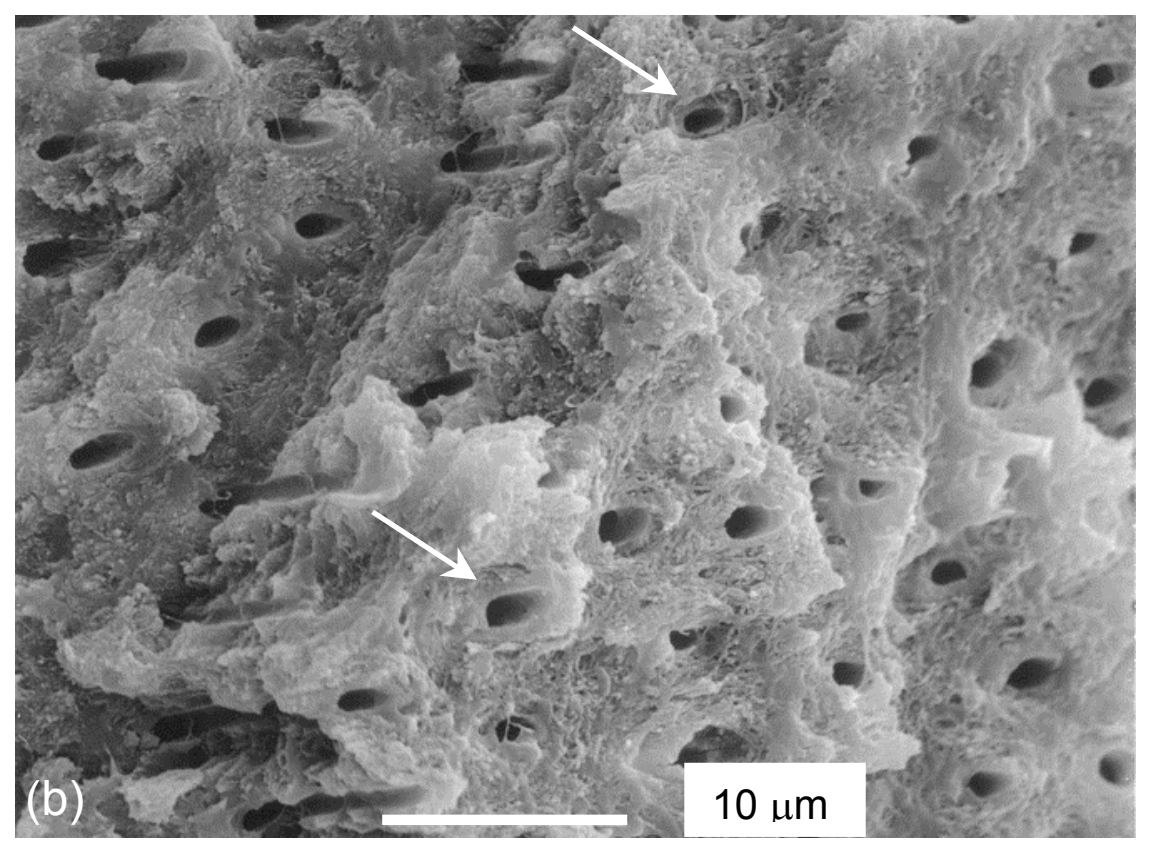

Figure 7: Higher magnification scanning electron micrographs of the cyclic fatigue region of the fracture surface, showing evidence of pullout of the peritubular dentin cuffs (indicated by white arrows). The nominal direction of crack growth is from left to right. 


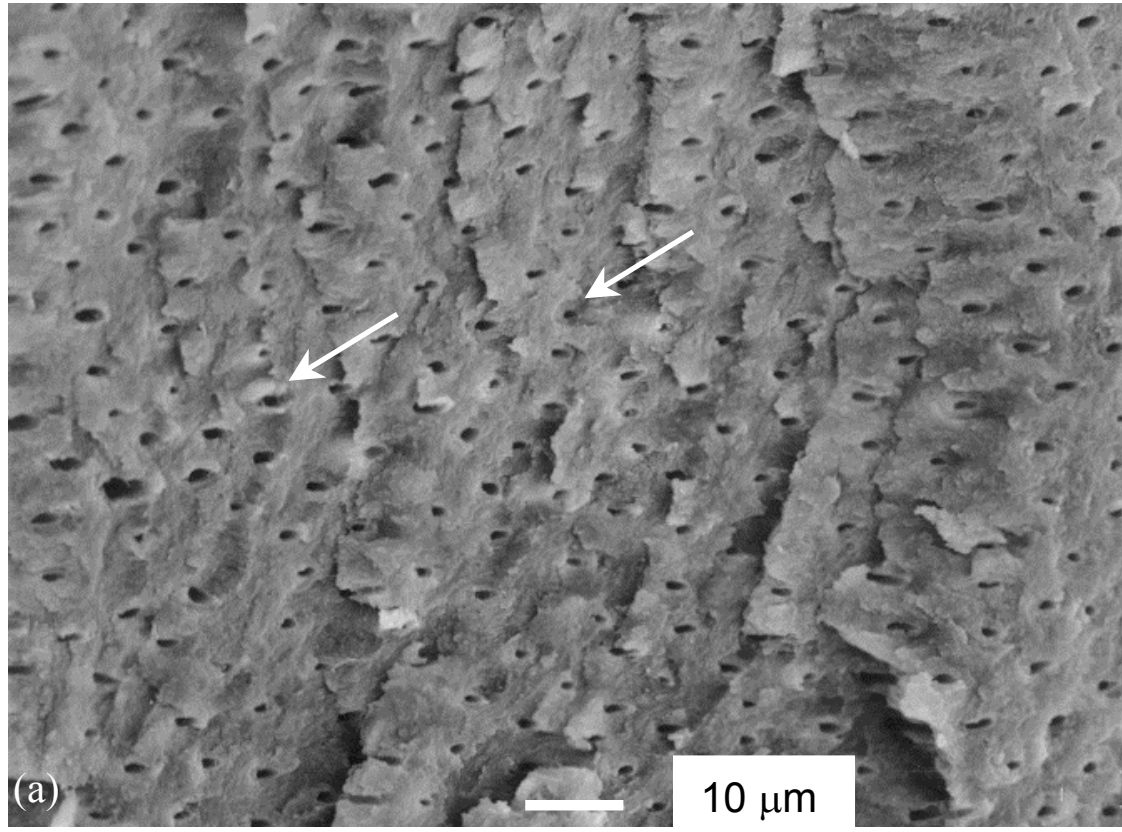

\section{Crack Growth Direction}

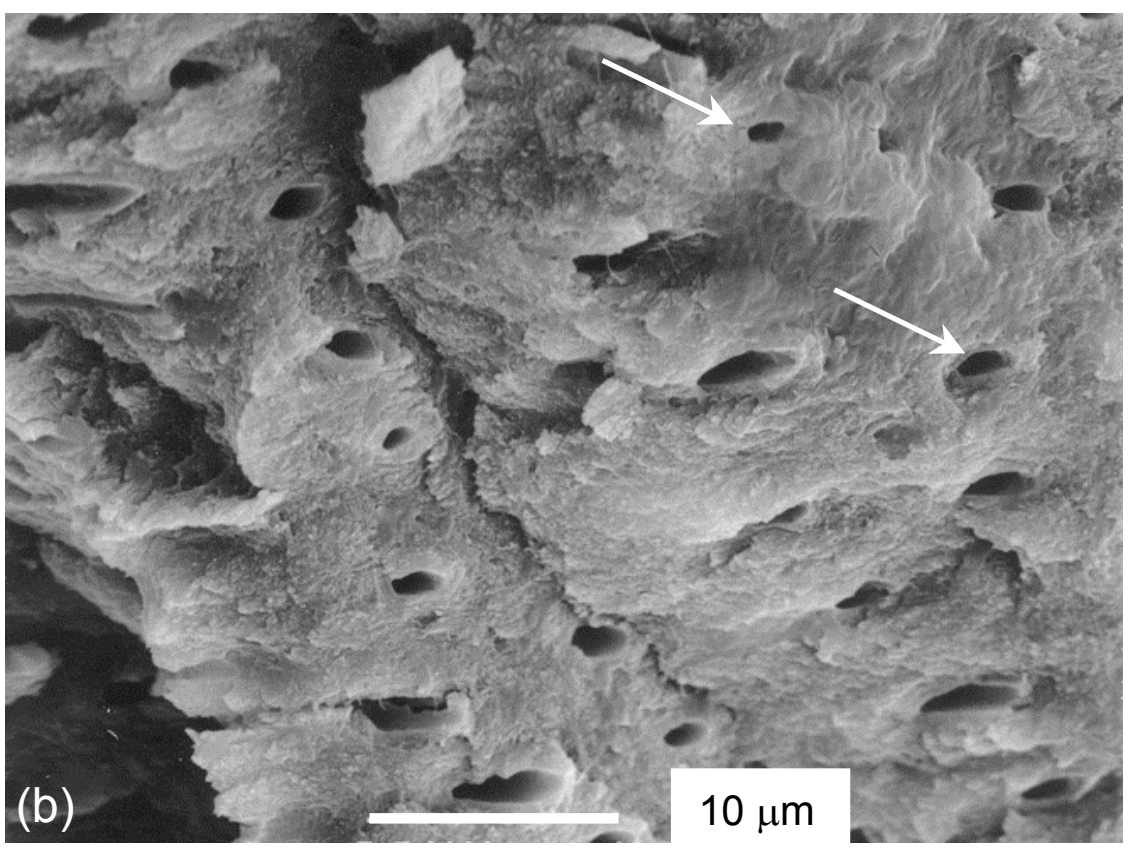

Figure 8: Corresponding scanning electron micrographs of the overload fracture region of the fracture surface. Although this fracture surface is macroscopically "rougher" than that of the fatigue fracture surfaces, the morphology is essentially identical. Some evidence of pullout of the peritubular dentin cuffs (indicated by white arrows) can again be seen. The nominal direction of crack growth is from left to right. 


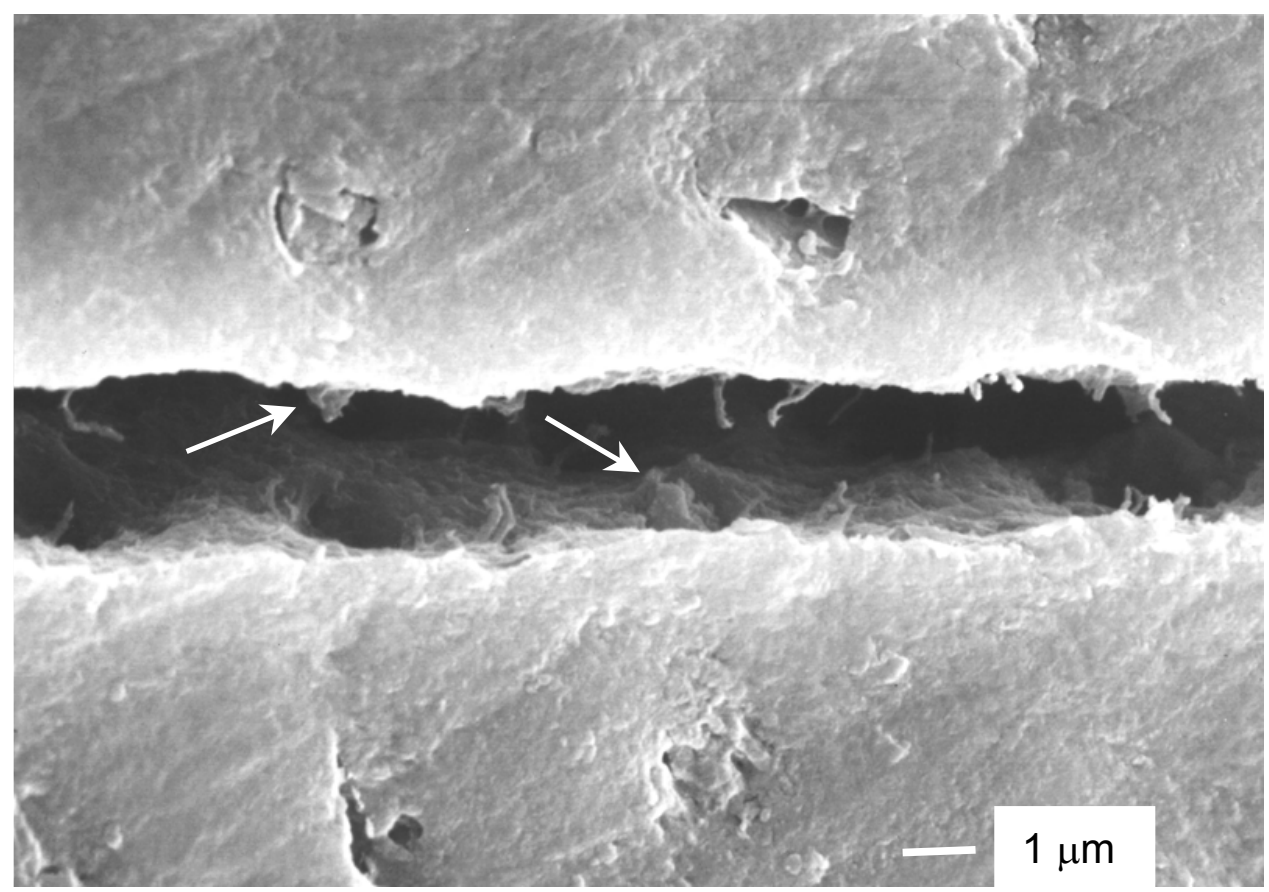

\section{Crack Growth Direction}

Figure 9: Scanning electron micrograph of a typical crack path of a fatigue crack through the dentin microstructure. Note the small degree of pullout of the peritubular dentin as indicated by the white arrows inside the crack. 

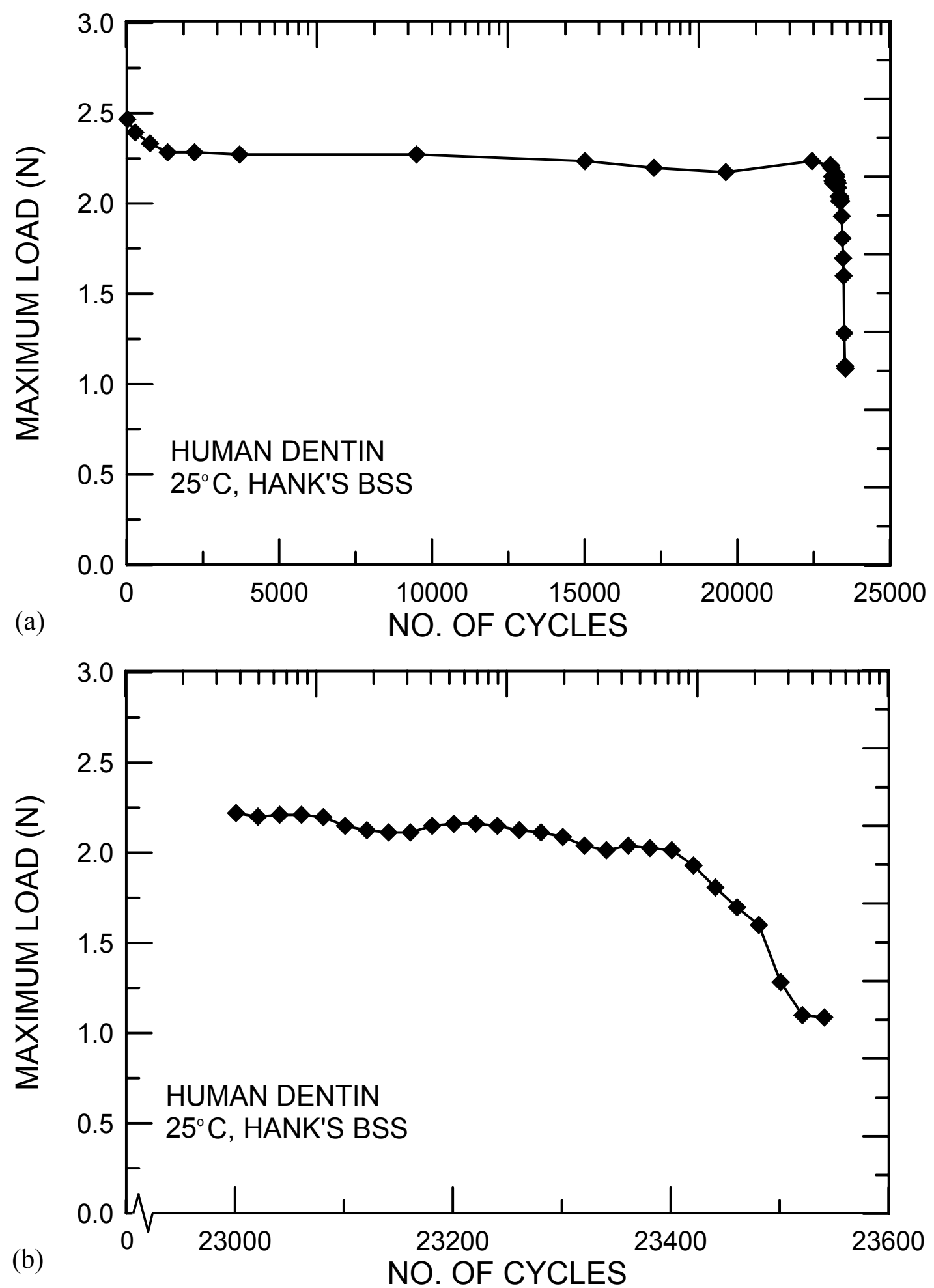

Figure 10: Typical stiffness-loss data obtained during a stress-life test, showing the drop in maximum load at constant displacement as a function of the number of loading cycles. (a) The stiffness is relatively constant for the majority of the test, until (b) it drops significantly near the end. This implies that the majority of the life is spent in initiating a growing crack. 


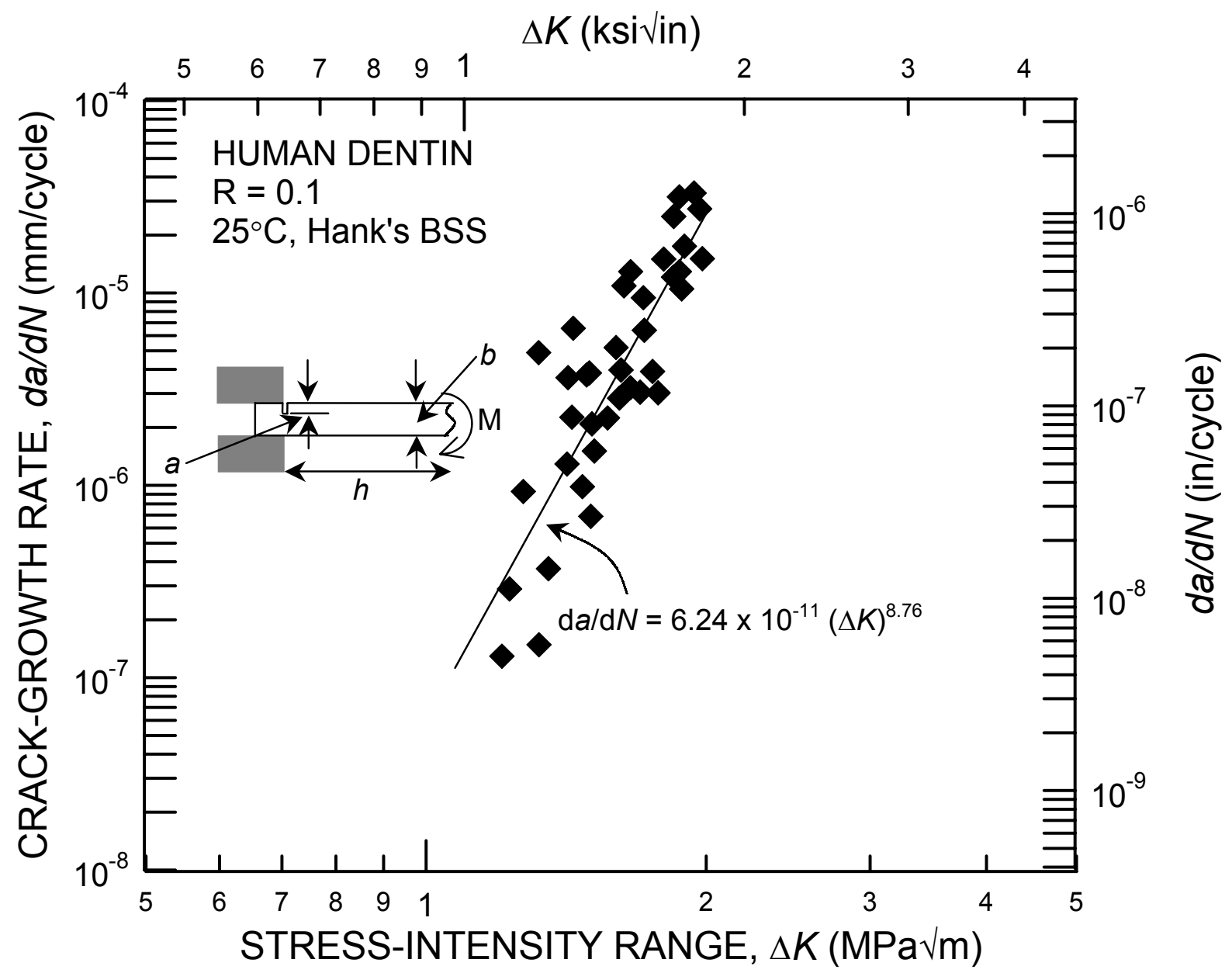

Figure 11: Plot of the variation in fatigue-crack growth rates, $\mathrm{d} a / \mathrm{d} N$, with the stressintensity range, $\Delta K$, for human dentin in HBBS at $R=0.1$. Results suggest a simple Paris power-law relationship, with an exponent of $m \sim 17$, for crack-growth behavior. The inset shows an illustration of the geometrical configuration used for these calculations. 


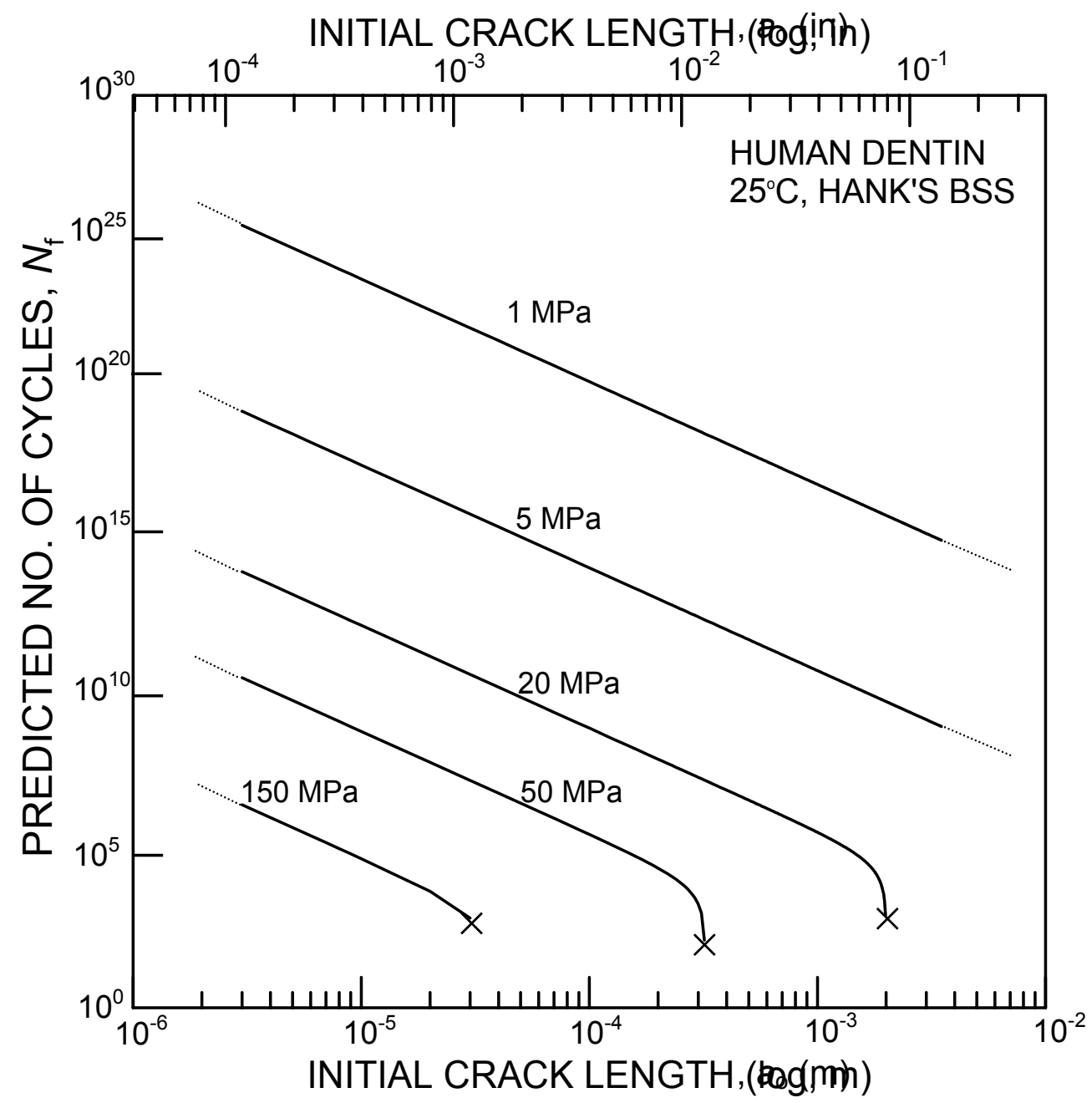

Figure 12: Predicted fatigue lives, in terms of the number of loading cycles $N_{\mathrm{f}}$, as a function of the initial flaw size, $a_{0}$, for a range of in-service stresses based on a hypothetical fracturemechanics life-prediction analysis for a tooth subjected to typical physiological stresses between 5-20 MPa. Time-based lifetime estimates are based on a nominal $10^{6}$ cycles per year. 